\title{
Theoretical recurrence risks for cleft lip derived from a population of consecutive newborns
}

\author{
ROMANO TENCONI, MAURIZIO CLEMENTI, AND LICIA TUROLLA \\ From Servizio di Genetica Medica, Dipartimento di Pediatria, Università di Padova, Italy.
}

SUMMARY Theoretical recurrence risks for cleft lip with or without cleft palate (CL(P)) were calculated from heritability estimates derived from a population of 203 newborns with CL(P) in a total of 220927 consecutive births in north-east Italy. Birth prevalence of CL(P) and the frequency of $\mathrm{CL}(\mathrm{P})$ in relatives of probands were estimated after exclusion of cases with $\mathrm{CL}(\mathrm{P})$ resulting from a known cause or pathogenesis. The method allowed estimation of the theoretical recurrence risk for any family by considering the total number of affected and unaffected first, second, and third degree relatives. The lower value of the theoretical risk compared to the empirical risk, obtained from retrospective data of selected families, was the result of methodological differences.

The estimate of recurrence risk in non-Mendelian disorders requires a reliable model of inheritance, a large unselected sample of affected subjects, and an accurate diagnostic procedure to obtain a sample as aetiologically homogeneous as possible.

Cleft lip with or without cleft palate $(\mathrm{CL}(\mathrm{P}))$, for which a multifactorial mode of inheritance is suggested by almost all authors, is a common congenital malformation. Quoted recurrence risks are usually empirical risks, though they have occasionally been theoretical risks, ${ }^{12}$ both types of risk derived ultimately from retrospective selected family data.

We present theoretical recurrence risks for cleft lip with or without cleft palate, calculated from data obtained from a population of consecutive newborns in north-east Italy.

\section{Methods}

The sample studied consisted of 203 newborns with CL(P) in a total of 220927 births (live and still) enrolled in the hospital based register of congenital malformations in north-east Italy (Veneto Region, Friuli-Venezia Giulia Region, and Bolzano Hospital) during the period from January 1981 to September 1986. Family history was obtained during interview with one or both parents. Personal history and an accurate description of the malformation were available from the standard registration form completed by the paediatrician within seven days of the birth. Skeletal $x$ ray survey, photographs,

Received for publication 2 March 1987.

Revised version accepted for publication 11 May 1987 chromosomal analysis, and necropsy were carried out as required for children with non-isolated $\mathrm{CL}(\mathrm{P})$. Birth prevalence and frequency of $\mathrm{CL}(\mathrm{P})$ in relatives were calculated after exclusion of cases with non-isolated $\mathrm{CL}(\mathrm{P})$ as part of a definite nosological entity (developmental field defect, malformation sequence or syndrome, association) or with an unusual facial cleft (median, oblique, transverse). Theoretical recurrence risks were estimated using Falconer's multifactorial model of liability to a disease ${ }^{3}$ and a computer program derived from Smith's method, ${ }^{4}$ as described by Barrai. $^{5}$

\section{Results}

A total of 154 cases had isolated CL(P), while in 45 the cleft was associated with at least one other malformation. In 14 of the latter the cause or pathogenesis was unknown (table 1). The overall birth prevalence was 0.92 per 1000 . For estimation of theoretical recurrence risks only the 168 probands with non-syndromic common CL(P) were used, giving a birth prevalence of 0.76 per 1000 . The distribution of probands according to severity of the malformation is given in table 2 .

The frequency of $C L(P)$ in first and second degree relatives of probands, and the corresponding heritability estimates, are shown in table 3 . The $1.5-$ fold heritability value associated with sibs and uncles/aunts compared with parents and grandparents may be explained by the reduced fitness of affected subjects, mainly females, in the past. For 
TABLE 1 Distribution of $C L(P)$ in newborns according to the type of cleft and cause.

\begin{tabular}{lrrrr}
\hline & No of affected & Males & $\%$ \\
\hline Common cleft & & 199 & 112 & 98 \\
Isolated CL(P) & & 154 & 89 & 76 \\
Non-isolated CL(P) & & 41 & 23 & 22 \\
$\quad$ Known cause or pathogenesis & 18 & & 16 & 15 \\
$\quad$ Chromosomal & 3 & & & \\
$\quad$ Amniotic rupture & 3 & & & \\
$\quad$ Hemifacial microsomia & 2 & & & \\
$\quad$ Meckel syndrome & 2 & & & \\
$\quad$ Frontonasal dysplasia & 1 & & & \\
$\quad$ EEC syndrome & 1 & & & \\
$\quad$ Saethre-Chotzen syndrome & 1 & 14 & 7 & 7 \\
$\quad$ Holoprosencephaly & & 4 & 1 & 2 \\
$\quad$ Unknown cause or pathogenesis & & 203 & 113 & 100 \\
Unusual facial cleft & & & & \\
Total affected & & &
\end{tabular}

TABLE 2 Numbers of probands with non-syndromic common $C L(P)$ according to severity of the malformation.

\begin{tabular}{lrrr}
\hline & $C L$ & $C L P$ & Total \\
\hline Unilateral & 65 & 59 & 124 \\
Bilateral & 6 & 36 & 42 \\
Unknown & 1 & 1 & 2 \\
Total & 72 & 96 & 168 \\
\hline
\end{tabular}

this reason we based theoretical recurrence risks on the weighted mean of the heritability estimates from sibs and uncles/aunts only. No division by sex was made since the sex ratio $(\mathrm{M} / \mathrm{F})$ of probands $(0 \cdot 56)$ was not significantly different from the sex ratio for total births in the region $(0 \cdot 51)$.

The frequency in first degree relatives was significantly dependent on the severity of the malformation in the proband when classified as CL and CLP $(0.5 \% \quad v 4.1 \% ; \mathrm{p}<0.025)$, unilateral and bilateral $(1.5 \% \vee 5.8 \% ; \mathrm{p}<0.025)$, or unilateral CL, unilateral CLP, and bilateral CLP $(1.6 \%$, $4 \cdot 2 \%$, and $6 \cdot 6 \%$ respectively; $p<0 \cdot 05$ ). Incidence in second degree relatives was independent of severity.

Examples of recurrence risks in families with different affected and unaffected members are given in table 4.

\section{Discussion}

Empirical recurrence risks for a multifactoriall controlled malformation can be derived only fronf very large samples. For this reason, empirical risk for $\mathrm{CL}(\mathrm{P})$ have been obtained from retrospective data on selected families (usually from surgicaf records $)^{6-8}$ covering a long period of time ${ }^{9-12}$ and different geographical areas. ${ }^{13} 14$ However $\overrightarrow{0}$ recurrence risks should be estimated for each population in recent years, using unselected famil|户 data and a sample as aetiologically homogeneous as. possible. A register of congenital malformations based on a large number of annual births in d restricted geographical area and in a well defined

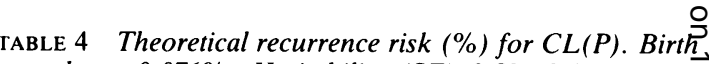
prevalence $0.076 \%$. Heritability (SE) $0.82(0.15)$.

\begin{tabular}{|c|c|c|c|}
\hline \multirow{2}{*}{$\begin{array}{l}\text { Other } \\
\text { relatives }\end{array}$} & \multicolumn{3}{|l|}{ Parents } \\
\hline & $\begin{array}{l}\text { Neither } \\
\text { affected }\end{array}$ & $\begin{array}{l}\text { One } \\
\text { affected }\end{array}$ & $\begin{array}{l}\text { Both } \\
\text { affected }\end{array}$ \\
\hline None affected & 0.08 & $2 \cdot 1$ & $26 \cdot 2$ \\
\hline ISA & $2 \cdot 4$ & $7 \cdot 6$ & $29 \cdot()$ \\
\hline ISA + ISnA & $2 \cdot 3$ & $7 \cdot 1$ & $28 \cdot 1$ \\
\hline $2 \mathrm{SA}$ & $7 \cdot 7$ & $14 \cdot()$ & $31 \cdot 3$ \\
\hline $1 S A+5 \operatorname{Sn} A$ & 1.9 & $5 \cdot 5$ & $24 \cdot 5$ \\
\hline
\end{tabular}

\begin{tabular}{|c|c|c|c|c|}
\hline & & $\begin{array}{l}\text { Same } \\
\text { family }\end{array}$ & $\begin{array}{l}\text { Other } \\
\text { family }\end{array}$ & \\
\hline ISDA & 0.5 & $2 \cdot 4$ & $9 \cdot 3$ & $28 \cdot 4$ \\
\hline ISDA+6SDnA & $0 \cdot 5$ & $2 \cdot 4$ & $9 \cdot()$ & $28 \cdot 2$ \\
\hline $1 S D A+1 S A$ & $4 \cdot 6$ & $8 \cdot 1$ & $16 \cdot 2$ & $30 \cdot 8$ \\
\hline $1 \mathrm{SDA}+1 \mathrm{SA}+2 \mathrm{SnA}$ & $4 \cdot 0$ & $7 \cdot 0$ & $14 \cdot 2$ & $29 \cdot 1$ \\
\hline INA & $0 \cdot 6$ & $4 \cdot 6$ & & $28 \cdot 4$ \\
\hline $1 \mathrm{NA}+6 \mathrm{NnA}$ & $0 \cdot 5$ & $4 \cdot 4$ & & $28 \cdot 0$ \\
\hline $1 \mathrm{NA}+1 \mathrm{SA}$ & 4.9 & $11 \cdot 4$ & & $30 \cdot 8$ \\
\hline $1 \mathrm{NA}+1 \mathrm{SDA}$ & 1.9 & $5 \cdot 0$ & $13 \cdot 6$ & $30 \cdot 3$ \\
\hline $1 \mathrm{NA}+1 \mathrm{SDA}+1 \mathrm{SA}$ & $7 \cdot 9$ & $12 \cdot 0$ & $20 \cdot 1$ & $32 \cdot 4$ \\
\hline ICA & $0 \cdot 2$ & $2 \cdot 3$ & $4 \cdot 8$ & $27 \cdot 5$ \\
\hline $1 \mathrm{CA}+6 \mathrm{CnA}$ & $0 \cdot 2$ & $2 \cdot 3$ & $4 \cdot 8$ & $27 \cdot 5$ \\
\hline $1 C A+1 S D A$ & 0.9 & $2 \cdot 5$ & $13 \cdot 7$ & $29 \cdot 3$ \\
\hline $1 \mathrm{CA}+1 \mathrm{NA}$ & $1 \cdot 1$ & 4.9 & $8 \cdot 7$ & $29 \cdot 5$ \\
\hline $1 \mathrm{CA}+1 \mathrm{SDA}+1 \mathrm{NA}$ & $2 \cdot 7$ & $5 \cdot 2$ & $18 \cdot 0$ & $31 \cdot 1$ \\
\hline $1 \mathrm{CA}+2 \mathrm{SA}$ & $9 \cdot 4$ & $14 \cdot 4$ & $18 \cdot 2$ & $32 \cdot 2$ \\
\hline
\end{tabular}

$\mathrm{S}=$ sib. $\mathrm{C}=$ cousin. $\mathrm{SD}=$ second degree relative. $\mathrm{N}=$ nephew. $\mathrm{A}=$ affected $\mathrm{nA}=$ not affected

TABLE 3 Frequency of $C L(P)$ among relatives and estimate of heritability.

\begin{tabular}{|c|c|c|c|c|}
\hline Relatives & $\begin{array}{l}\text { Affected/ } \\
\text { total }\end{array}$ & $\begin{array}{l}\text { Frequency }(\%) \\
\text { in relatives } \\
(S E)\end{array}$ & $h^{2} \quad(S E)$ & $\begin{array}{l}h^{2} \text { weighted } \\
\text { mean }(S E)\end{array}$ \\
\hline Mothers & $2 / 161$ & $1.24(0.87)$ & $(0.54(0 \cdot 16)$ & \multirow{4}{*}{$0.82\left((0.15)^{*}\right.$} \\
\hline Fathers & $4 / 162$ & $2.46(1.22)$ & $(0.70(0.12)$ & \\
\hline Sibs & $5 / 108$ & $4 \cdot 64(2 \cdot 02)$ & $0.86(0.12)$ & \\
\hline Uncles/aunts & $6 / 888$ & $0.68(0.28)$ & $0.81(0.17)$ & \\
\hline
\end{tabular}

(SE) standard error.

Standard error only for sibs and uncles/aunts. 
period of time, with quality control for detecting malformation syndromes, is the best source for obtaining a prevalence rate and family data from unselected consecutive affected newborns. Our estimate of overall birth prevalence $(0.92$ per 1000$)$ was close to figures found in other Italian and European malformation registers. ${ }^{15}$ The 'true' birth prevalence $(0.76$ per 1000$)$ was the lowest rate compared with those reported in previous genetic studies (table 5).

The frequency of $\mathrm{CL}(\mathrm{P})$ in the relatives of our probands was similar to that previously reported. A significant positive association between severity of the malformation in the proband and the frequency of $\mathrm{CL}(\mathrm{P})$ in relatives was found only for first degree relatives, confirming an earlier suggestion that the severity of the malformation in the proband had an effect on the proportion of affected first degree relatives. ${ }^{12}$ Heritability estimates, calculated from birth prevalence and frequency of $\mathrm{CL}(\mathrm{P})$ among relatives, have varied widely both between and within various studies, but different sampling methodologies might in part account for these differences. In this respect, it is noteworthy that our heritability estimate is similar to that reported in the Hungarian population using data from a congenital malformation register. ${ }^{16}$

The difference between heritability estimates derived from different kinds of relative in our study and other reports ${ }^{6814}$ may be due, as previously suggested, ${ }^{12}{ }^{14}$ to reduced fitness of affected subjects, mainly in the past (grandparents) and in females (mothers and grandmothers). The theoretical recurrence risks obtained in this study are lower than, but close to, figures reported in two earlier studies $^{12}$ in which the same theoretical approach was applied. The higher empirical recurrence risks (table 5) compared to theoretical recurrence risks are explained by the inclusion of families with multiple affected subjects in calculating the former. In fact, Woolf ${ }^{14}$ found an overall frequency of CL(P) of $4.0 \%$ in the sibs of probands, while the frequency of $\mathrm{CL}(\mathrm{P})$ in the newly born sibs of probands with no previous family history of CL(P) was $2 \cdot 2 \%$, and the frequency of $\mathrm{CL}(\mathrm{P})$ in sibs born after the second affected sib was $14 \cdot 6 \%$. Similar results have been obtained by other authors. ${ }^{1013}$

In genetic counselling, the exact recurrence risk is not generally required by the consultand and its approximate value is usually sufficient. However, the method used allows estimation of the theoretical recurrence risk for any family, by considering the total number of affected and unaffected first, second, and third degree relatives. For example, the theoretical recurrence risk for a family with both the father and one paternal second degree relative

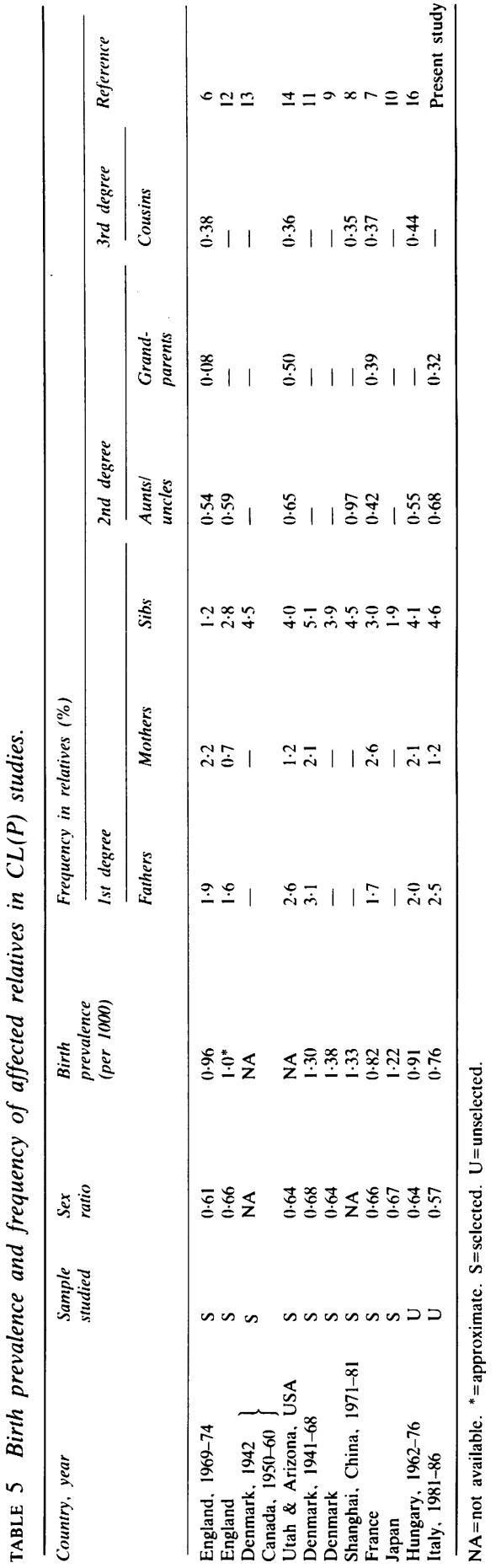


affected is $2 \cdot 4 \%$, while it is $9.3 \%$ when both the father and one maternal second degree relative are affected.

We would like to thank all the paediatricians, obstetricians, and cytogeneticists collaborating in the epidemiological study on congenital malformations in north-east Italy.

\section{References}

' Bonaiti-Pellié C, Smith C. Risk table for genetic counselling in some common congenital malformations. J Med Genet 1974;11: 374-7.

2 Bonaiti-Pellé C, Feingold J, Briard ML, Frézal J. Risque de recurrence dans quelques malformations congenitales: anencephalic, spina-bifida, fentes labiales et palatinc. Arch $\mathrm{Fr}$ Pediatr 1976;33:973-86.

${ }^{3}$ Falconer DS. The inheritance of liability to certain disease estimated from the incidence among relatives. Ann Hum Genet 1965:29:51-76.

${ }^{4}$ Smith C. Recurrence risks for multifactorial inheritance. Am J Hum Genet 1971:23:578-88.

5 Barrai I. Introduzione alla genetica dei caratteri quantitativi. Padova: Piccin Editorc, 1980.

6 Bear JC. A genetic study of facial clefting in Northern England. Clin Genet 1976:9:277-84.

7 Bonaiti-Pellié C, Briard ML, Feingold J, et al. An cpidemiological and genetic study of facial clefting in France. I. Epidemiology and frequency in relatives. J Med Genet 1982:19: 8-15.
${ }^{8}$ Hu DN, Li JH, Chen HY, et al. Genetics of cleft lip and cleft $\stackrel{\mathbb{P}}{?}$ palate in China. Am J Hum Genet 1982:34:999-10(1)2.

9 Bixler D, Fogh-Andersen P. Conneally PM. Incidence of cleft lip and palate in the offspring of cleft parents. Clin Geneto 1971:2:155-9.

10 Koguchi H. Population data on cleft lip and cleft palate in the Japanese. In: Mclnick M, Bixler D, Shiclds ED. eds. Etiology of cleft lip and cleft palate. New York: Alan R Liss, 1980:297-323.

11 Melnick M, Bixler D, Fogh-Andersen P. Conneally PM. Cleft lip + /- cleft palate: an overview of the literature and an analysises of Danish cases born between 1941 and 1968. Am J Med Genet $\vec{\circ}$ 1980;6:83-97.

12 Carter CO, Evans K, Coffey R, Fraser Roberts JA, Buck A, $\overrightarrow{\vec{\omega}}$ Fraser Roberts M. A threc generation family study of cleft lip. with or without cleft palate. J Med Genet 1982:19:246-61.

13 Curtis E, Fraser FC, Warburton D. Congenital cleft lip and palate. Am J Dis Child 1962:102:853-7.

14 Woolf CM. Congenital cleft lip: a genetic study of 496 propositi.u J Med Genet 1971;8:65-71.

15 De Wals P, Dolk H, Weatherall JAC, et al. Prevalence of congenital anomalies in 19 Eurocat Centers, 1979-1982. In: Detu Wals P, Weatherall JAC, Lechat MF, eds. Registration ofo congenital anomalies in Eurocat Centers 1979-1983. Louvain-laNeuve: Cabay, 1985:146-202.

${ }^{16}$ Czcizel A. Studics of cleft lip and cleft palate in East European populations. In: Melnick M, Bixler D. Shiclds ED, cds. Etiologyof cleft lip and cleft palate. New York: Alan R Liss, 1980:249-96.

Correspondence and requests for reprints to Professor R Tenconi, Servizio di Genetica Medica, Dipartimento di Pediatria, Via Giustiniani 3, $351288^{\circ}$ Padova, Italy. 